\title{
Stapedius reflex in multiple sclerosis
}

\author{
K . HE S S \\ From the Medical Research Council, Hearing and Balance Unit, Institute of Neurology, \\ National Hospital, Queen Square, London
}

\begin{abstract}
S U M MARY An analysis was carried out of recordings of the crossed stapedial reflex response in a series of normal subjects and 30 patients with multiple sclerosis. Parameters measured included latency, contraction time, amplitude, and relaxation time. Criteria derived from the normal group and applied to the multiple sclerosis group showed clear evidence of abnormality in 10 patients. This can be attributed to lesions in the pathways of the second and third order neurones in the trapezoid body and superior olivary complex. Present evidence suggests that further refinements in the measurement technique might significantly increase the detection rate of abnormalities in multiple sclerosis.
\end{abstract}

The long held notion that the primary function of the stapedius reflex is to protect the ear against the onslaught of injurious noise has been called into question recently by a number of studies, in particular those of Borg and Zakrisson (1975) which have shown that vocalisation at all measureable levels induces activity of the stapedial reflex. The same authors (1973) made the further interesting observation that discrimination of speech sounds is significantly impaired in patients with stapedius paralysis caused by Bell's palsy. The new evidence, incomplete as it is, strongly suggests that the function of the stapedius reflex is a particularly complex one and has more to do with speech production or reception in one way or another than with protection. More importantly, however, it is now well established that the neuronal organisation of the stapedial connections at the level of the brainstem is of a widespread complexity far in excess of what might be expected for the transmission of a simple reflex. The crossed stapedius reflex, thoroughly investigated in rabbits by Borg (1973), is subserved by a direct pathway of four neurones - the primary auditory afferent, the ventral cochlear nucleus neurones with their axons reaching the contralateral medial superior olive via the trapezoid body, and the neurones in the medial superior olive, finally con-

Address for correspondence and reprint requests: Dr $K$. Hess, Kantonsspital Zürich, Neurologische Universitätsklinik und Poliklinik, 8006 Zürich, Rämistrasse 100, Switzerland.

Accepted 8 September 1978 tacting ipsilaterally the stapedius motor neurones in the facial nucleus. A parallel slower pathway has also been noted. This complexity, which is assumed to be similar in humans, raises the interesting possibility that stapedial reflex function as revealed by more refined techniques might be particularly susceptible to discrete lesions of the brainstem and, therefore, helpful in localisation and diagnosis. Indeed this is well supported by recent pilot clinical studies carried out by Bosatra et al. (1975), Colletti (1975) and Hall and Jerger (1976). The investigations to be described here have, therefore, been carried out upon a group of patients with predominantly a definite diagnosis of multiple sclerosis with a view to determining whether or not abnormalities of the stapedius reflex could be demonstrated and, if so, how helpful they would be likely to be in the identification of this condition.

\section{Method}

\section{APPARATUS}

The activity of the middle ear muscles was recorded as changes of the acoustic impedance of the ear. Impedance audiometry was carried out by means of an electroacoustic impedance bridge (Madsen, type ZO-7o), and an associated pure tone audiometer. The output from the bridge was connected to a 4-channel Medelec oscilloscope with fibre-optic recorder. Reflex responses were recorded on one channel, the stimulus was recorded 
on the second channel, and a third unmodulated channel was used to provide a baseline as an aid to measurement.

\section{PROCEDURE}

Initially, pure tone air conduction thresholds at $500,1000,2000$, and $4000 \mathrm{~Hz}$ were established. For all measurements of the stapedius reflex, the stimulus was presented to one ear and the probe tip was sealed in the opposite ear (contralateral mode). Routine impedance measures for the pressure-compliance function (tympanometry) as described by Jerger (1970) were carried out. Stapedius reflex thresholds were established, the threshold being defined as the lowest hearing level at which a positive or negative deflection of the balance meter of the impedance bridge (sensitivity level at mark 3 or 4) could be observed reliably, both ascending and descending stimuli being used. Stapedius reflex curves were registered at a frequency of $1000 \mathrm{~Hz}$ and at intensity levels of $+10 \mathrm{~dB}$ above threshold and at $110 \mathrm{~dB}$, for each ear separately. Under these conditions it was considered that the stapedius reflex alone was tested, the tensor tympani reflex not being elicited. Stimulus duration was $1.0 \mathrm{~s}, 10 \mathrm{~s}$ being used for reflex decay measurements. Paper speed was $50 \mathrm{~mm}$ per second, and $5 \mathrm{~mm}$ per second for reflex decay measurements. Rise and fall time of the pure tone stimuli was 10 milliseconds. Several recordings were carried out at each test level, the intervals between being randomly varied between one second and one minute in order to avoid adaptation.

\section{MEASUREMENTS}

From each test at least two samples free of visible artefacts were selected for study. Artefacts which had to be avoided were small arterial pulsations, small jaw or throat movements, and leakage of the sealed-off external meatus. With the use of a cursor specially devised for this purpose, the following four measurements were obtained from each test, the first three being illustrated in Fig. 1a.

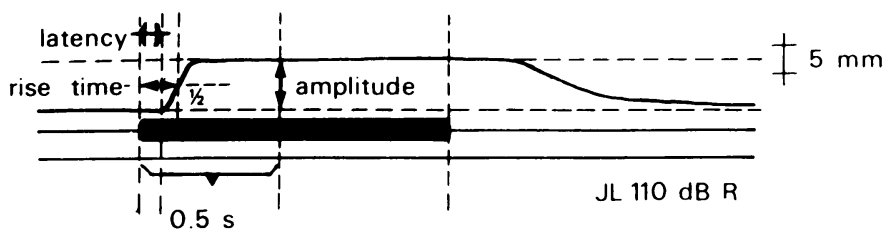

(a)
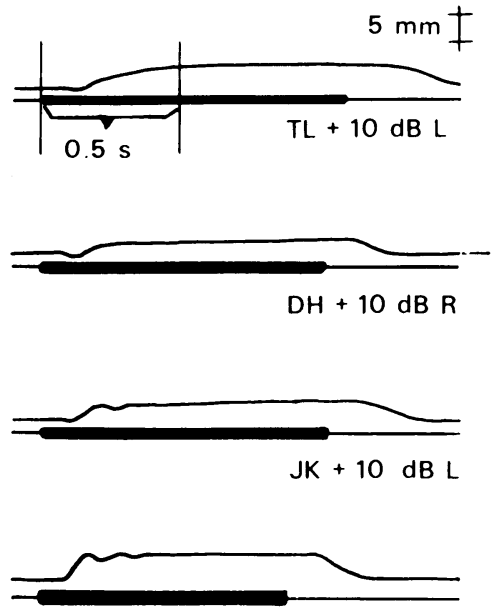

$M G+10 d B R$

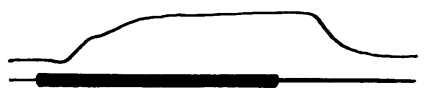

(b)
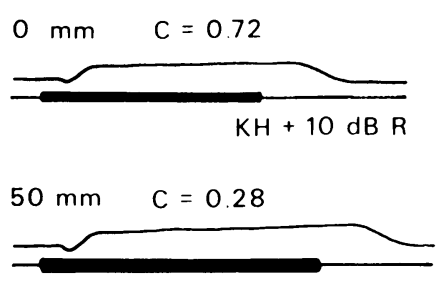

$100 \mathrm{~mm} \quad \mathrm{C}=0.12$

$150 \mathrm{~mm} \quad \mathrm{C}=0.05$

$200 \mathrm{~mm} \quad \mathrm{C}=0$
Fig. 1 Normal stapedius reftex curve. (a) Technique of measurement; (b) normal variants; (c) influence of the compliance on the curve shape. Middle ear pressure in $\mathrm{mmH}_{\mathrm{O}} \mathrm{O}$, compliance $\mathrm{C}$ in $\mathrm{ml}$. Calibration of the abscissa: the ordinate in $\mathrm{mm}$. $+10 \mathrm{~dB}$, $50 \mathrm{~mm}=1$ second; calibration of $110 \mathrm{~dB}=$ stimulus intensities. $R, L=$ right, left side. 
1. Latency from the onset of the stimulus to the initial negative or positive deflection of the stapedius reflex response.

2. Half rise time defined as the time taken for the response to attain half its maximum amplitude measured from the stimulus onset.

3. Amplitude measured 0.5 seconds after the onset of the stimulus.

4. "Half life", as a measure of the reflex decay was defined as the time taken for the response to fall to half its maximal amplitude during the application of a 10 seconds stimulus at $+10 \mathrm{~dB}$ stimulus intensity (Anderson et al., 1969).

If there were different measures from several such samples, the responses were averaged.

Norris et al. (1974) use the term "relexation time" as a measure of the reduction of the amplitude after the stimulus offset. In our patients, as well as in those reported by Hall and Jerger (1976), relaxation time proved to be so particularly variable that it was excluded as a quantitative criterion from this study. In some instances, however, it was judged qualitatively, as being normal or delayed.

\section{Subjects}

\section{CONTROL SUBJECTS}

Twelve hospital personnel and students within the age range 21-46 years (mean 30 years) acted as control subjects. There were six men and six women. Middle ear pressure, tympanometry, and compliance were normal in all but one ear, 23 ears, therefore, being used. Hearing levels were normal in all.

\section{INFLUENCE OF SENSORINEURAL DEAFNESS}

In a study of 23 patients with sensorineural deafness ranging from $40-85 \mathrm{~dB}$ at $1000 \mathrm{~Hz}$, Norris et al. (1974) found significant differences of the stapedius reflex tracing only for the relaxation time, whereas latency and rise times were not significantly delayed. These results are in agreement with our experience. Thus, a preliminary study of four patients with unilateral or bilateral sensorineural deafness of $20-30 \mathrm{~dB}$ at $1000 \mathrm{~Hz}$ yielded stapedius reflex curves which showed some delayed relaxation times as the only abnormality. In three patients with slight hearing loss (15-20 dB at $1000 \mathrm{~Hz}$ ), no abnormality at all was found. It would seem reasonable to infer, therefore, that hearing loss in itself does not affect the stapedius reflex curve, at least up to hearing levels of $30 \mathrm{~dB}$.

\section{PATIENTS}

Thirty randomly chosen patients, aged $16-61$ years (mean 39 years), comprising 15 men and 15 women were studied. Twenty patients had clinically definite, eight patients probable, and two patients possible, multiple sclerosis as defined by McAlpine et al. (1972). In none was there a known previous ear disease. None was deaf on clinical examination. Middle ear pressure, tympanometry, compliance, and audiograms were normal bilaterally in 26 patients, the tympanogram being from the type A after Jerger (1970) and the compliance being between 0.28 and $1.72 \mathrm{ml}$ (Morrison, 1975). Two patients had a slight deafness. In two patients, the stapedius reflex tracings on one side were rejected because of compliance that was slightly too low. Unless mentioned, patients had no symptoms or signs of facial paralysis. Apart from these criteria, the following data were analysedduration of disease, number of episodes (unless progressive course), and presence or absence of brainstem signs.

For practical reasons, the present paper conforms to the convention that the right ear is indicated when the bridge is connected to the right ear and the sound is introduced to the left ear, and vice versa.

\section{Results}

CONTROL SUBJECTS

In order to establish limits of normality, mean values, standard deviations, and $95 \%$ confidence limits were determined on the 12 control subjects (23 ears). These values are shown in Table 1 together with the results of a separate study carried out earlier on 29 ears (Ceryan, personal communication). Although it was not possible to combine

Table 1 Stapedius reflex curve parameters. Mean values, standard deviations, and $95 \%$ confidence limits from 12 subjects (23 ears). In brackets values from 15 normal subjects (29 ears) investigated by Ceryan (1976, personal communication)

\begin{tabular}{llll}
\hline Parameters & Mean & $\begin{array}{l}\text { Standard } \\
\text { deviation }\end{array}$ & $\begin{array}{l}95 \% \text { confidence } \\
\text { limits }\end{array}$ \\
\hline $\begin{array}{l}\text { Latency } \\
\text { (ms) }\end{array}$ & & \\
$\quad$ at $+10 \mathrm{~dB}$ & 90.2 & \pm 17.7 & $55-126$ \\
at $110 \mathrm{~dB}$ & 74.0 & \pm 14.8 & $44-104$ \\
$\begin{array}{l}\text { Half rise time } \\
\text { (ms) }\end{array}$ & & \\
$\begin{array}{l}\text { at }+10 \mathrm{~dB} \\
\text { at } 110 \mathrm{~dB}\end{array}$ & $201(191)$ & $\pm 36.5( \pm 48)$ & $126-274(99-283)$ \\
$\begin{array}{l}\text { Amplitude } \\
\text { (mm deflection) }\end{array}$ & & $\pm 30.4( \pm 35)$ & $98-219(90-230)$ \\
at $+10 \mathrm{~dB}$ & $4.1(4.0)$ & $\pm 1.5(1.2)$ & $1.1-7.2(1.7-6.3)$ \\
at $110 \mathrm{~dB}$ & $7.0(7.5)$ & $\pm 2.3(2.0)$ & $2.4-11.7(3.5-11.5)$ \\
\hline
\end{tabular}


both sets of data it will be seen that they are closely comparable.

The curves in normal subjects can be characterised by the two types illustrated in Fig. 1 ( $a$ and $b$ ) showing rapid initial deflection at $110 \mathrm{~dB}$ and less rapid at $+10 \mathrm{~dB}$. In a few cases, some oscillations in the initial deflection (Fig. 1b) as described by Møller (1958), were observed. Latency was found to vary in two out of 23 ears, from one reflex response to the other, over a range of $25 \mathrm{~ms}$ at most. On the other hand, reflex latency depends on stimulus intensity, growing shorter with higher intensities (Metz, 1951) and varying from about $150 \mathrm{~ms}$ near threshold to $25 \mathrm{~ms}$ at high stimulus intensities (Møller, 1958; Bosatra et al., 1975; Hall and Jerger, 1976).

An initial weak negative peak occurred in approximately $50 \%$ of the subjects in this group, particularly at the $+10 \mathrm{~dB}$ level. The general impression is that this was related in some way to compliance values and this finds support in the tracing shown in Fig. 1(c) where variations in the tracing with compliance values are self-evident. Furthermore, it is of some note that particularly marked negative peaks appeared in the tracings of certain subjects rejected from this study on account of abnormally low compliance values. Although no effect upon latency could be detected, the possibility remains that negative peaks could materially affect the half rise determination, and for this reason in determining confidence limits three subjects showing negative peak values greater than $1.0 \mathrm{~mm}$ in amplitude were excluded.

\section{CRITERIA FOR ASSESSMENT OF A PATHOLOGICAL}

STAPEDIUS REFLEX CURVE

Because of the relatively wide distribution of normal values, fairly stringent criteria were adopted in the assessment of pathology. Thus in the multiple sclerosis group a stapedius reflex curve was considered abnormal only if at least one of the measured parameters at stimulus intensity $110 \mathrm{~dB}$ was abnormal. Abnormal is defined for rise time and amplitude as being outside of the $95 \%$ confidence limits for normal values, and for the latency as being $140 \mathrm{~ms}$ or more at $+10 \mathrm{~dB}$ and $120 \mathrm{~ms}$ or more at $110 \mathrm{~dB}$ stimulus intensitythat is, $15 \mathrm{~ms}$ above the confidence limits. Absence of any reaction to stimuli as high as $110 \mathrm{~dB}$ was not judged as abnormal because of its known occurrence in a small percentage of normal subjects in the age range relevant to this study (Jerger, 1970). By contrast a stapedius reflex response present at $100 \mathrm{~dB}$ but outside normal limits at $110 \mathrm{~dB}$ was taken to be abnormal. According to Anderson et al. (1969) there is normally no measurable "reflex decay" at $1000 \mathrm{~Hz}$ stimuli. Therefore, any clear-cut decay was taken to be abnormal.

NORMAL STAPEDIUS REFLEX CURVES IN PATIENTS WITH MULTIPLE SCLEROSIS

On these criteria stapedius reflex curves were found to be normal in 20 out of 30 patients. Mean duration of disease in these patients was 7.5 years, the mean number of episodes 3.2, two patients having a primary progressing course. Diagnosis was definite in 14, probable in four and possible in two cases. Fourteen patients $(70 \%)$ had brainstem signs such as spontaneous nystagmus, internuclear ophthalmoplegia, seventh nerve symptoms, and broken-up following movements of the eyes.

PATIENTS WITH PATHOLOGICAL STAPEDIUS REFLEXES Ten patients $(33 \%)$ had pathological stapedius reflex curves (Table 2). The mean duration of disease was 6.7 years and the mean number of episodes 2.9 , one patient having a primary progressing course. Diagnosis was definite in six and probable in four cases. Only two of the patients were over 50 years old, whereas five patients of the group with normal stapedius reflex were over 50 , the oldest being 61 years old. Nine patients $(90 \%)$ had signs of a brainstem lesion.

Because of the known influence of drugs on the stapedius reflex (Bosatra et al., 1975), care was taken in the selection of patients, that none of them were on treatment with barbiturates or other drugs acting on the brainstem.

In nine of the 10 patients the stapedius reflex was bilaterally deranged at both stimulus intensities. In the remaining patient (case 4) the stapedius reflex on one side was not classified because of pathological compliance. The threshold values of the patients fell within normal limits or were only slightly raised (case 10). In addition only one patient showed any evidence of pathological reflex decay.

As will be seen from Table 2 the most marked departures from normality occurred in the form of the response tracing the half rise time being abnormal in nine patients and a negative deflection occurring in one. Relaxation time seemed to be delayed in some tracings with pathological rise time.

Latencies were prolonged unilaterally or bilaterally and amplitudes abnormally low in five patients. Since both occurred in combination with abnormal rise times, the question arises as to whether or not one exerted any influence upon the other. Consider first the latency. Although it is to 
be expected that an increase in latency will prolong the rise time, it seems unlikely that any clear functional relationship exists between the two. Thus normal latencies were frequently followed by abnormal rise times, and in one case a prolonged latency was followed by a normal rise time.

Similarly, in respect of amplitude it is clear from Table 2 that there was no systematic correlation between pathological rise time and amplitude although a small amplitude was normally preceded by a pathological rise time and appears to be secondary to it.
TYPICAL PATHOLOGICAL TRACING TYPES

With the exception of two tracings derived from the right ear of patient 1 , showing only a reduction in amplitude, the remaining 35 tracings from 10 patients could be categorised into three types as shown in Fig. 2.

If the pathological values are summarised schematically (Figure 3), a typical pathological pattern of stapedius reflex tracing in patients with multiple sclerosis emerges-namely, a slow rise time preceded by a pathological latency, and abnormally low amplitude of response. Pathological

Table 2 Pathological stapedius reflex curves in 10 multiple sclerosis patients (roman numbers $=$ normal, italic numbers $=$ abnormal)

\begin{tabular}{|c|c|c|c|c|c|c|c|c|c|c|c|c|}
\hline \multirow{3}{*}{$\begin{array}{l}\text { Case } \\
\text { no }\end{array}$} & \multirow{3}{*}{$\begin{array}{l}\text { Age } \\
(y r)\end{array}$} & \multirow[t]{3}{*}{$\operatorname{Sex}$} & \multirow{3}{*}{$\begin{array}{l}\text { Middle ear } \\
\text { compliance } \\
(m l)\end{array}$} & \multirow{3}{*}{$\begin{array}{l}\text { Threshold } \\
\text { of StR at } \\
1000 \mathrm{~Hz}\end{array}$} & \multicolumn{2}{|c|}{ Latency $(m s)$} & \multirow{2}{*}{\multicolumn{2}{|c|}{$\begin{array}{l}\text { Half rise time } \\
(\mathrm{ms})\end{array}$}} & \multicolumn{2}{|c|}{ Amplitude $(\mathrm{cm})$} & \multirow{3}{*}{$\begin{array}{l}\text { Decay } \\
\text { at } \\
+10 \mathrm{~dB}\end{array}$} & \multirow[t]{3}{*}{ Special observations } \\
\hline & & & & & $1 / 0 d B$ & $+10 d B$ & & & $110 \mathrm{~dB}$ & $+10 \mathrm{~dB}$ & & \\
\hline & & & & & & & $110 \mathrm{~dB}$ & $+10 d B$ & & & & \\
\hline \multirow[t]{2}{*}{1} & \multirow[t]{2}{*}{41} & \multirow[t]{2}{*}{$\mathrm{F}$} & R 1.16 & $85 \mathrm{~dB}$ & 120 & 170 & 160 & 220 & 0.2 & 0.1 & $\varnothing$ & \multirow{6}{*}{$\begin{array}{l}\text { Right mild lower motor } \\
\text { neurone facial weakness }\end{array}$} \\
\hline & & & L 0.8 & $90 \mathrm{~dB}$ & 150 & 180 & 230 & 380 & 0.15 & 0.07 & $\varnothing$ & \\
\hline \multirow[t]{2}{*}{2} & \multirow[t]{2}{*}{56} & \multirow[t]{2}{*}{$\mathbf{M}$} & R 1.08 & $90 \mathrm{~dB}$ & 90 & 180 & 320 & 330 & 0.22 & 0.1 & $\varnothing$ & \\
\hline & & & L 0.58 & $85 \mathrm{~dB}$ & 70 & 80 & 220 & 290 & 0.4 & 0.25 & $\varnothing$ & \\
\hline \multirow[t]{2}{*}{3} & \multirow[t]{2}{*}{42} & \multirow[t]{2}{*}{$\mathrm{F}$} & R 0.51 & $85 \mathrm{~dB}$ & 60 & 70 & 240 & 230 & 0.33 & 0.16 & $\varnothing$ & \\
\hline & & & L 0.48 & $85 \mathrm{~dB}$ & 60 & 65 & 285 & 320 & 0.18 & 0.1 & $\tilde{\varnothing}$ & \\
\hline \multirow[t]{2}{*}{4} & \multirow[t]{2}{*}{37} & \multirow[t]{2}{*}{$\mathbf{M}$} & R 0.26 & $90 \mathrm{~dB}$ & 70 & 80 & \multicolumn{2}{|c|}{ Not used } & \multicolumn{2}{|c|}{ Not used } & $\varnothing$ & Low right compliance \\
\hline & & & L 0.66 & $95 \mathrm{~dB}$ & 95 & 100 & 320 & 300 & $<0.1$ & $<0.1$ & & but normal hearing \\
\hline \multirow[t]{2}{*}{5} & \multirow[t]{2}{*}{24} & \multirow[t]{2}{*}{$\mathrm{F}$} & R 0.89 & $95 \mathrm{~dB}$ & 95 & 100 & 275 & 345 & 0.45 & 0.25 & $\varnothing$ & Bilateral hearing \\
\hline & & & L 0.59 & $95 \mathrm{~dB}$ & 110 & 115 & 400 & 380 & $<0.1$ & $<0.1$ & $\widetilde{\varnothing}$ & loss $15 \mathrm{~dB}$ at $1000 \mathrm{~Hz}$ \\
\hline \multirow[t]{2}{*}{6} & \multirow[t]{2}{*}{16} & \multirow[t]{2}{*}{$\mathbf{M}$} & R 1.58 & $80 \mathrm{~dB}$ & 90 & 240 & 260 & 395 & 1.0 & 0.7 & + & Steplike rise in some \\
\hline & & & L 1.44 & $80 \mathrm{~dB}$ & 140 & $200-360$ & 265 & $380-495$ & 0.5 & 0.6 & + & curves \\
\hline \multirow[t]{2}{*}{7} & 52 & $\mathrm{~F}$ & $\mathbf{R} 0.78$ & $90 \mathrm{~dB}$ & 95 & 140 & 280 & 380 & 0.3 & 0.14 & $\varnothing$ & Right hearing loss \\
\hline & & & L 1.49 & $100 \mathrm{~dB}$ & 140 & - & 390 & - & 0.29 & - & $\tilde{\varnothing}$ & $20 \mathrm{~dB}$ at $1000 \mathrm{~Hz}$ \\
\hline 8 & 40 & $\mathrm{~F}$ & R 0.86 & $80 \mathrm{~dB}$ & 60 & 65 & 310 & 520 & 0.24 & 0.12 & $\varnothing$ & \\
\hline & & & L 0.54 & $75 \mathrm{~dB}$ & 65 & 65 & 225 & 300 & 0.35 & 0.25 & $\varnothing$ & \\
\hline 9 & 32 & $\mathrm{~F}$ & R 0.89 & $80 \mathrm{~dB}$ & 80 & 90 & 245 & 320 & 0.9 & 0.3 & $\varnothing$ & Left residual lower \\
\hline & & & L 1.33 & $80 \mathrm{~dB}$ & 80 & 90 & 255 & 350 & 0.4 & 0.12 & $\widetilde{\varnothing}$ & motor neurone facial \\
\hline 10 & 32 & $\mathbf{M}$ & $\begin{array}{l}\text { R } 0.71 \\
\text { L } 0.92\end{array}$ & $\begin{array}{l}100 \mathrm{~dB} \\
10 J \mathrm{~dB}\end{array}$ & $\begin{array}{r}150 \\
80\end{array}$ & - & $\mathrm{Nes}$ & tive - & $\begin{array}{l}\text { Negat } \\
\int \text { deflec }\end{array}$ & $\begin{array}{l}\text { ve - } \\
\text { on - }\end{array}$ & - & \\
\hline
\end{tabular}

StR $=$ stapedius reflex

Type 1 (abnormal rise time)
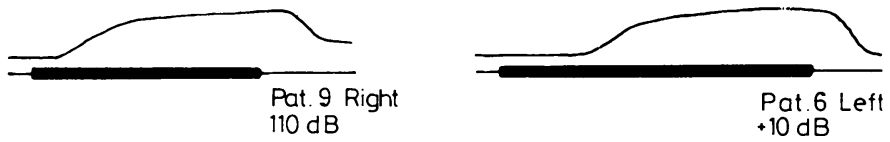

Type 2 (abnormal rise time and amplitude)
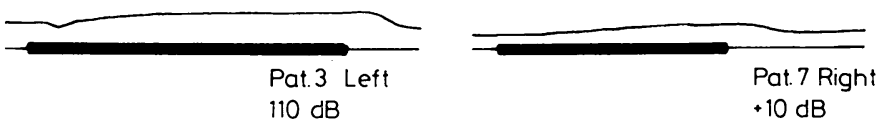

Fig. 2 Typical curve shapes of pathological stapedius reflexes. On the left side with normal, on the right side with pathological latency.

Type 3 (shallow, mainly negative deflection)
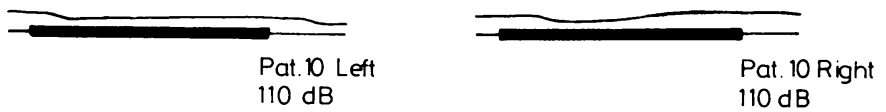


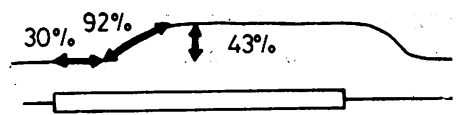

Fig. 3 Typical abnormalities of the stapedius reflex curves in patients with multiple sclerosis. Percentage numbers extracted from Table 2.

latencies occurred more often at $+10 \mathrm{~dB}$ stimulus intensity, whereas the remaining abnormalities were present in about the same proportion at both stimulus intensities. Evidence of pathology, however, was more prominent at $110 \mathrm{~dB}$ and will be considered later.

\section{REPRODUCIBILITY}

Good reproducibility of the stapedius reflex curve has been reported by Borg (1973) and Møller (1958). This aspect was studied in six ears (three normal subjects, three patients) by setting the ear probe a second time in the same ear. The interval was normally between 0.5 and 1 hour; in one normal ear it was two months. The shape of the stapedius reflex curve remained exactly the same in every ear tested. Latency was particularly constant with a mean variability of about $7.5 \%$ (32 measurements) and a maximum of $10 \%$. Halfrise times at $110 \mathrm{~dB}$ stimulus intensity were similarly constant, the variability being not more than $10 \%$ (nine measurements). At both stimulus intensities the mean variability of the amplitude was $15 \%$ ( 39 measurements), with a maximum of $20 \%$. Half rise time at $+10 \mathrm{~dB}$ stimulus intensity proved to be particularly variable, with a mean value of nearly $20 \%$ and in one instance a maximum of $30 \%$. This most probably reflects errors in measurement resulting from the smallness of the curves. Because of this and the fact that abnormal rise times at $+10 \mathrm{~dB}$ were consistently associated with abnormal rise time at $110 \mathrm{~dB}$ the former were used for control purposes only.

\section{Discussion}

These results, incomplete as they are, have provided clear evidence that clinically silent lesions of the brainstem can give rise to derangements of the stapedius reflex.

The most common abnormality was an increased rise time of the reflex response which was found in each of the 10 patients, and bilaterally in all but one of them. Similar results have been reported by Bosatra et al. (1975) and Colletti (1975).

In a third of these curves, amplitude was pathologically low, reduced amplitude almost always being associated with pathological rise time. Apart from this, the other most significant abnormality was increased latency found in about a third of the curves. Extremely high variability of pathological latency values was found in one patient (case 6), measurements at $+10 \mathrm{~dB}$ ranging from 200 to $360 \mathrm{~ms}$, the curve shape remaining unchanged on each occasion. Latencies of this order have been reported also by Bosatra et al. (1975) in patients with multiple sclerosis. The reason for this as well as for some variability of latency in normal subjects is not clear. As with acoustic evoked responses, arousal mechanisms do not, in our experience, exert much influence on the stapedius reflex curve although influence of higher centres on the fast-conducting reflex pathway are not well known (Borg, 1973).

Pathological reflex decay was found in only one patient of the present series. This patient (case 6) presented without any hearing loss, suggesting that decay of the stapedius reflex, as with pathological tone decay, can occur in the absence of hearing loss in retrocochlear lesions. On the other hand, pathological decay of the stapedius reflex response has been reported by Anderson et al. (1969) and by Colletti (1975) in multiple sclerosis patients with mild to moderate bilateral hearing loss.

In two out of three patients the rise time was more deranged on the side of a mild lower neurone facial palsy. From this, it was felt that lower motor neurone facial weakness can influence the rise time of the stapedius reflex curve and has to be accounted for. The question arises as to whether an isolated lesion of stapedius motorneurones in the seventh cranial nerve nucleus or on its way through the brainstem can give rise to stapedius reflex abnormalities without affecting the bulk of the other motorneurones and hence escape clinical signs of lower motor neurone palsy. Assuming a similar organisation of the facial nucleus in humans to that in rabbits, this seems unlikely because stapedius motorneurones in rabbits are scattered within the seventh nerve subnuclei and not organised in a single subnucleus (Borg, 1973).

Although comparisons with the results of experimental brainstem lesions in rabbits (Borg, 1973) are hazardous, some points are worth mentioning. Pathological rise time in rabbits was consistently found only following a complete midline transection of the trapezoid body from the ventral side between the pyramidal tracts, at the level of the superior olivary complex. Pathological rise time was accompanied by decrease of the crossed response amplitude and some increase in latency, but only a small rise in threshold and relaxation 
time. This bilateral pattern was found in a high proportion of our patients. It corresponds to the configuration found by Bosatra et al. (1975) in patients with what is termed the "acute nucleoreticular vestibular syndrome" and in normal subjects after barbiturate administration. The suggestion is that this is the effect of blockage of the fast-conducting reflex pathway. From the clinical point of view it could give useful indication of the localisation of an otherwise silent lesion.

A further pattern of pathological stapedius reflex, namely unilateral reduction in amplitude with only a small rise in threshold, was found in lesions of the ventral cochlear nuclei in rabbits. With this lesion, however, one would also expect unilateral hearing loss to be present. There was no patient of the present series with this pattern.

Raised threshold of the stapedius reflex was found in lesions of the trapezoid body near the ventral cochlear nuclei and in lesions of the medial superior olive in rabbits. Such lesions could account for the pathological stapedius reflex curves associated with slightly raised reflex threshold found in two patients (cases 4 and 10) with normal hearing.

Extremely high latency values were not reported by Borg. In our patients, pathological latency was unrelated to any particular type of tracing (Fig. 2). This in turn suggests that pathological latency values could be caused by demyelination at different sites of the reflex pathway and are not attributable to specific lesions.

An incidence of pathological findings of $33 \%$ might be deemed disappointingly low in a group of patients in whom brainstem lesions are to be expected. By comparison, the early auditory evoked potentials have been found to be pathological in $80 \%$ of patients with brainstem lesions resulting from multiple sclerosis (Robinson and Rudge, 1977). It has to be recalled, however, that the criteria adopted here were particularly rigid. One of the limiting factors in this respect has been the difficulty in obtaining accurate measurements upon tracings of small dimensions, and here in particular there is obvious scope for considerable refinements using a larger display.

In addition, current improvements in impedance audiometry equipment are already affording a greater degree of stability than was found in this study. It seems highly likely, therefore, that the detection rate could be much increased. In this event there is hope that the simple and relatively inexpensive test procedures outlined here could assume increasing importance in the diagnosis of multiple sclerosis.

I would like to express my gratitude to Dr J. D. Hood, Director of the Medical Research Council Hearing and Balance Unit, for his advice and help, to Dr Kerim Ceryan for his instruction in stapedial reflex measurement, and to $\mathrm{Mr} \mathrm{E}$. Trinder for his technical assistance.

\section{References}

Anderson, H., Barr, B., and Wedenberg, E. (1969). Intra-aural reflexes in retrocochlear lesions. In Nobel symposium 10, Disorders of the Skull Base Region, pp. 49-55. Edited by C. A. Hamberger and J. Wersäll. Almqvist and Wiksell: Stockholm.

Borg, E. (1973). On the neuronal organisation of the acoustic middle ear reflex. A physiological and anatomical study. Brain Research, 49 101-123.

Borg, E., and Zakrisson, J.-E. (1973). Stapedius reflex and speech features. Journal of Acoustic Society of America, 54, 525-527.

Borge, E., and Zakrisson, J.-E. (1975). The activity of the stapedius muscle in man during vocalization. Acta Otolaryngologica, 79, 325-333.

Bosatra, A., Russolo, M., and Poli, P. (1975)) Modifications of the stapedius muscle reflex under spontaneous and experimental brainstem impairment. Acta Otolaryngologica, 80, 61-66.

Colletti, V. (1975). Stapedius reflex abnormalities in multiple sclerosis. A udiology, 14, 63-71.

Hall, J. W., and Jerger, J. (1976). Acoustic reflex characteristics in spastic dysphonia. Archives of Otolaryngology, 102, 411-415.

Jerger, J, (1970). Clinical experience with impedance audiometry. Archives of Otolaryngology, 92, 311324.

McAlpine, D., Lumsden, C. E., and Acheson, E. D. (1972). Multiple Sclerosis: A Reappraisal. Churchill Livingstone: Edinburgh.

Metz, O. (1951). Studies on the contraction of the tympanic muscles as indicated by changes in the impedance of the ear. Acta Otolaryngologica, 39, $397-405$.

Møller, A. R. (1958). Intra-aural muscle contraction in man, examined by measuring acoustic impedance of the ear. Laryngoscope, 68, 48-62.

Morrison, A. W. (1975). Management of Sensorineural Deafness. Butterworths: London and Boston.

Norris, T. W., Stelmachowicz, P., Bowling, C., and Taylor, D. (1974). Latency measures of the acoustic reflex. Audiology, 13, 464 469.

Robinson, K., and Rudge, P. (1977). Abnormalities of the auditory evoked potentials in patients with multiple sclerosis. Brain, 100, 19-40. 